\title{
Can the Context be Commensurable with the World in Heideggerian Sense?*
}

\author{
Qu Ping \\ Department of Foreign Languages, Henan Institute of Engineering, Zhengzhou, P.R. China 451191 \\ pingyuanmei686@163.com
}

\begin{abstract}
Understanding of being as world-disclosure existentially determines both the kind of being of humans and the kind of being of entities which we encounter within the world; this means that understanding of being is essentially equivalent to the human being's being-in-the-world. The aim of study is to enhance pragmatics philosophically. Some methods as deduction, illustration are used. The result is to develop linguistic education.

Keywords: understanding, context, world, commensurable

\section{Introduction}

Understanding of being as world-disclosure existentially determines both the kind of being of humans and the kind of being of entities which we encounter within the world; this means that understanding of being is essentially equivalent to the human being's being-in-the-world. Or to put it in another way, the constitutive items of this unitary phenomenon shown in the compound expression - being-in-the-world — are so existentially close in terms of interconnection that when we speak of one we are always speaking of the others or the whole unity. For example, "being" not only always means the being of entities already understood in the world discovered by being but also the being of understanding in the world; these two kinds of being in every case correspond to each other; the world always means the world understood in terms of being; being or understanding always means the world understood as (in) the world. In short, each item of this unity has the full right to represent the other items in the phenomenological world. Being-in-the-world is phenomenologically constituted that it ontologically roots in the human being in the world. This unique relationship can be comprehended as what Heidegger calls the hermeneutic circularity.
\end{abstract}

\section{Understanding as an Envelope Word}

It is by virtue of this unique existential-hermeneutic circularity that being and the world is equally commensurable: the "world" is the world which has been lit up or disclosed by being; otherwise there will be no such a world; on the other hand, the "being" must rise up in the world. Accordingly, when we speak of "being" we essentially means "the being of the world". So, it is obvious that the denotations of being and the world are the same. Additionally, the unitary phenomenon
- being-in-the-world, as explained, is another name for the human being or Dasein; the human being in its essence is constituted by his understanding of being. Therefore, when we speak of being-in-the-world we are always speaking of understanding of being and the human being itself. To sum the upshots we can obtain another model implied or buried in Heidegger's hermeneutic phenomenology: this model runs being (the human being)-beings (entities within-the-word)world (the phenomenological world). Either the unitary phenomenon - being-in-the-world or the hermeneutic model — being-entities-world - unexceptionally stresses the foundation of the world in the human being's understanding of being. What is the foundation of the world in the human being's understanding of being? To this question Heidegger has an unambiguous answer: "The world itself isnot an entity within the world; and yet it is so determinative for such entities that only in so far as 'there is' a world can they be encountered and show themselves, as entities which have been uncovered" (BT, 102; italics added). Bearing in mind what Heideggerian sense of "world" is, we now move back to the question of "What is context" in Sperber \& Wilson.

\section{Context: The Range of Understanding}

What is context? To this question Sperber \& Wilson have a definite answer: "The set of premises used in interpreting an utterance (apart from the premises that the utterance in question has been produced) constitutes what is generally known as the context" (RC, 15; italics added). Then, what is the meaning of "premise"? Premise means "something assumed or taken for granted", or "presupposition", therefore we can say, if a context is constituted by a set of premises, it is also constituted by a set of assumptions; and assumption, as discussed above, means the "conceptual representations of the actual world". Here, the term of "representation", on Sperber \& Wilson's view, refers to the kind of psychological activities. Accordingly, not only the assumption but also the context is posited in the realm of psychology. Therefore, when we ask such a question as: Wherefrom does "the set of premises used in the act of interpretation"' come? The immediate and unexamined answer is of course: It comes from psychology. It is not surprising that, in Sperber \& Wilson's work Relevance: Communication and Cognition, we can read "A context is a psychological construct" (ibid; italics added). Let

\footnotetext{
* The paper is the initial accomplishment of the program assigned by Henan Science and Technology Department in 2013: A Study on the Translators in Phenomenological Perspective in Henan. No : 132400410300
} 
us put together the forementioned three definitions: "assumptions as the conceptual representations of the actual world" (1); "a context as the set of premises used in interpreting" (2); and "premise as something assumed or taken for granted" (3), for a closer examination, we can, then, discover that the context is not anything but assumption. Therefore, in Sperber \& Wilson's work there runs such a claim as a gloss: "a subset of the hearer's assumptions about the world" (ibid; italics added) immediately following "A context is a psychological construct”. Furthermore, since the context, like the assumption, lies in the terrain of psychology, so to say that a context influences or determines an interpretation of an utterance is of course equal to saying that psychology rather than the world outside psychology influences or determines an interpretation of an utterance. For this reason, Sperber \& Wilson can have such an assertion: "It is these assumptions, of course, rather than the actual state of the world, that affect the interpretation of an utterance” (ibid; italics added).

\section{The Commonness of the Two Concepts}

So far Sperber \& Wilson's definition of context as “a psychological construct, a subset of assumptions about the world" (RC, 15) becomes clear. In their sense, a context is obviously distinctive from our ordinary ideas of it: the physical environment; the geographical place; the objective roundness or the environment objectively considered; "the totality of those entities which can be present-at-hand within the world" (BT, 185). Gutt has his explanation at this point, "Hence in relevance theory context does not refer to some part of the external environment of the communication partners, be it the text preceding or following an utterance, situational circumstances, cultural factors, etc.” (Gutt, 2006: 27); on the contrary, the context in relevance theory refers to a subset or part of the communication partners' "assumptions about the world" (ibid). In short, the context in relevance theory signifies the psychological construct or psychologically symbolicalized system. In comparison with assumption, a context is usually larger than an assumption; and yet it can be smaller when the assumption becomes as large as the world. Both the definition and these relationships of the context time and again remind of Heideggerian sense of "the world within the world". Furthermore, the "world" in the expression "assumptions about the world" in the definition of context, does not refer to the total sum of entities pieced together any longer; but rather a world of assignment-relations or reference-relations, namely, a world of symbolic structure in virtue of the "contamination" of assumption. Along this train of thought, the context can be reasonably construed in Heideggerian sense of "the world within the world", if the psychological condition of context were removed off. A context is like a world which has been brought closer than the farthest, primary, amorphous, preconceptual, global world. For example, in Heideggerian sense, the world is not an entity but a global, farthest, symbolic structure which is made up by various assignment-relations in terms of the in-order-to-be or for-the-sake-of-which; yet within this primary, farthest, global world there are always such possibilities which make a less-dim, closer world constituted around something that upon which an interpretation or an assumption is to be projected for the time being. For example, "in public we may have the public we-world, in private, one may possess the private one's closest (domestic) world in the primary world" (BT, 93). In our everydayness or the world of phenomenology, there is always such a closer world, because there are always the possibilities which can hook up our attention to some particular entities within the world; it will be very abnormal and unimaginable that everything within the world lies equal in deseverance in the relations of significance of the world; or in other words, that an entity within the world as an involvement within all the involvements of the world has the same chance to bring it closer (express, interpret) as any one of other involvements. Quite the contrary, there are always some entities rather than others which can, proximally and for the most part, be attuned-to or brought closer for the sake of which that the human being is to be. This kind of phenomenon has been disclosed by Heidegger when he relates the derivative relationship between understanding and interpretation (See BT, 191; and my discussion on pages 78-80 in this thesis). Under this condition, the most relevant involvement of all the involvements of the world will in the first instance be brought closer and thereby constitutes a comparatively less-dim, closer world in the primary world to meet the purpose of a for-thesake-which. This kind of a less-dim, closer world which is held in the primary, farthest, global world is, as mentioned, in accordance with the law of economy. So, it is apparent that there exists a commensurable relationship between Heideggerian sense of world and Sperber \& Wilson's sense of context. Yet there is still a difference, and this difference in its essence can classify Heidegger and Sperber \& Wilson into different camps of philosophy: Heideggerian sense of world is basically founded upon the human being's being-in-the-world before the subject-object split, it is the most ontological world - being-ontological world; therefore, it must be the primordial source from which a less-dim, closer world is derived. On the other hand, Sperber \& Wilson's sense of context only concerns psychology, and is therefore a merely derivative world which ultimately finds its way into Heidegger's being-ontological world. Accordingly, Sperber \& Wilson's sense of context is commensurable with this kind of a derivative, less-dim, closer world. That is why we are careful in choosing such expression as "the world within the world", and regard the first "world" as the context.

So far we have not discussed the real meaning of "the actual world" in the definitions of "assumption" and "context”. Upon what ground can Sperber \& Wilson claim that assumptions mean "thoughts treated by the individual as representations of the actual world" and thoughts mean “conceptual representations"? The unexamined or overhasty answer is probably their context, or their psychological construct, which their work - Relevance: Communication and Cognition consistently tells us all the time. In their mind, the context or the psychological construct seems the fundamental source into which all kinds of "Communication 
and Cognition" ultimately find their ways; and conversely, it is the problematic of "Communication and Cognition" which Sperber \& Wilson take as their exclusive task to investigate that accordingly turns their work into "Communication and Cognition". Therefore, their communication and cognition, as have been explained and demonstrated, must be founded upon their own context - the psychological construct. But is it true that the context is the fundamental basis or the original source from which all kinds of "Communication and Cognition" are derived? The answer to this question can be surely "No" in the light of Heidegger's existential being-ontology. The expressions - "representations of the actual world" and "conceptual representations" used to define the terms "assumption" and "context" - speak of their derivative character, because, according to Heidegger's existential beingontology, long before the "conceptual representations" and "representations of the actual world" are constituted we have already been being-in-the-world, which means that we have already been disclosed by our understanding of being in the world before the "conceptual representations" are constituted. This "conceptual representations" is therefore an obviously derivative mode of the primary understanding of being. And even "the actual world" is also a derivative mode of Heidegger's sense of world, for how do we know that a world is "the actual world"? To say that a world is "the actual world" means that the world has already been discovered by an understanding of being in the name of "being-actual". Therefore, "the actual world" is already a derivative world whose primordial world is the pre-thematic, pre-conceptual understanding of being, which remains so and so before it gets interpreted conceptually. The primary intelligible world is a network of relations but not an explicit conception of "beingactual". Accordingly, when an explicit conception is bestowed to a world by interpretation, this always means that part of the original world is thereby brought closer by the process of interpretation. To express this bringing-close process in a formula, we can get it as follows: to interpret it as the actual world. Therefore, "the actual world" is not the primordial world in the sense of being-in-the-world. If, as Sperber \& Wilson tell us, "A context is a psychological construct" (RC, 15), this psychological construct, then, should be in accordance with Heideggerian interpreting or bringing-close world which is inherently founded upon the pre-conceptual world of understanding of being.

\section{Conclusion}

So far we have managed to open a passage from Sperber \& Wilson's context to Heidegger's world. A context, even if it is a derivative mode of Heidegger's world, should carry with itself the basic characters as its ultimate foundation possesses; it therefore should be a world of symbolic structure which is constituted by various signifying relations or involvements for the sake of which that the human being who is. In this symbolically constituted structure (context), we can find these elements "not limited to information about the immediate physical environment or the immediately preceding utterances: expectations about the future, scientific hypotheses or religious beliefs, anecdotal memories, general cultural assumptions, beliefs about the mental state of the speaker, may all play a role in interpretation" (RC, 15-16) at the time when this structure (context) is hooked up or set in motion by some particular assumptions about some particular utterances. Yet, in order to further our study on the derivative commensurability between Heidegger and Sperber \& Wilson in this regard, it is necessary to come near to Sperber \& Wilson's another important constitutive item - the "relevance" - in the relationship between assumption and context.

\section{References}

[1] Venuti, Lawrence. (ed.) The Translation Studies Reader. Routledge: London and New York, 2000.

[2] Culler, Jonathan. On Deconstruction: Theory and Criticism after Structuralism. Beijing: Foreign Language Teaching and Research Press, 2004.

[3] Heidegger, Martin. Being and Time. John Macquarrie \& Edward Robinson (trans.) China Social Sciences Publishing House Chengchengh Books Ltd., 1999.

[4] Gutt, Ernst-August. Translation and Relevance-Cognition and Context. Shanghai: Shanghai Foreign Language Education Press, 2004.

[5] Heidegger, Martin. Poetry, Language, Thought. Albert Hofstadter (trans.) Beijing: China Social Sciences Publishing House Chengcheng Books Ltd., 1999.

[6] Robinson, D. The Translator's Turn. Beijing: Foreign Language Teaching and Research Press, 2006.

[7] Gadamer, Gorg. Truth and Method. Garpett Barden \& John Cimming (trans.) Beingjing: China Social Sciences Publishing House Chengch Books Ltd., 1999. 